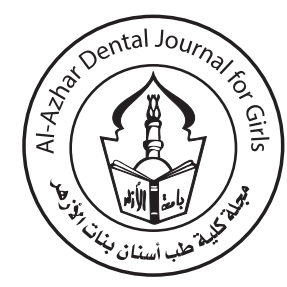

\title{
Efficacy of Stem Cells and Corticotomy on the Rate of Canine Retraction
}

\author{
Yousra M. Saad ${ }^{*}$, Ahmed E. Salama ${ }^{2}$, Samir A. Ibrahim ${ }^{3}$, Nahed M. Adly ${ }^{4}$, Ahmed F. Abd El Azeem
}

Codex : $16 / 22.01$

azhardentj@azhar.edu.eg

http://adjg.journals.ekb.eg

DOI: $10.21608 /$ adjg.2021.22651.1216

Pediatric Dentistry \& Orthodontics ( Pediatric Dentistry, Orthodontics)

\section{KEYWORDS}

Canine retraction, Stem cells,

Piezocorticotomy, Split mouth.

\begin{abstract}
Purpose:In this study we were aiming to determine and evaluate the efficacy of the stem cells and corticotomy on the rate of canine retraction. Materials and Methods: 22 patients from both genders were selected. The age range of the selected cases was (15-20 years). All patients were examined to fulfill the inclusion criteria. These patients were divided into two groups; control group and intervention group. Split mouth technique was adopted in the intervention group to minimize the variables. In the intervention group one side received piezocorticomy only, while the other side received piezocorticotomy and stem cells. In control group conventional orthodontic canine retraction was carried out. To measure the rate of canine retraction; impression and casts were taken every one month till complete canine retraction. Casts were then digitally scanned and superimposed to digitally measure the rate of canine retraction. Results: Regarding maxilla the results showed no significant difference in the total rate of canine retraction of all comparative groups. Regarding mandible, the difference was significant higher between both stem cell and piezo groups in comparison to the control group. The canine retraction rate was higher in maxilla and mandible with stem cell injection than in the Piezo group of both arches; this difference in maxilla was in the first month of retraction only, but in mandible it was in the first two months. Conclusions: addition of stem cells to piezocorticotomy showed highest canine retraction rate in early months of retraction.
\end{abstract}

- Paper extracted from Masters thesis titled "Efficacy of Stem Cells and Corticotomy on the Rate of Canine Retraction".

1. BDS 2012, Faculty of Oral and Dental Medicine.MSA University.

2. Professor and Head of Orthodontics Department, Faculty of Dental Medicine for Girls, Al-Azhar University, Cairo, Egypt.

3. Professor of Orthodontics.Faculty of Dental Medicine for Girls, Al-Azhar University, Cairo, Egypt.

4. Lecturer of Oral Surgery.Faculty of Dental Medicine for Girls, Al-Azhar University, Cairo, Egypt.

5. Assistant researcher of regenerative medicine and genetics, Oro-dental Genetics Departement, Human Genetics division, National Research Center, Cairo, Egypt.

*Corresponding author email: yousra.moh.1989@gmail.com 


\section{INTRODUCTION}

Duration of orthodontic treatment; became the first and most important to all of the patients. Moreover, duration longevity of the treatment in many cases may lead to multiple side effects; as decay, recession of the gingival margins or even may cause root resorption. That's why there was a demand calling for to find the best method to speed up the movement and also having the least disadvantages as possible or even no disadvantages ${ }^{(1)}$.

One of the surgical methods of accelerating canine retraction is corticotomy; in Corticotomy Assisted Orthodontics CAO; the cortical layer is cut or perforated to the depth of the medullary bone which is preserved ${ }^{(2)}$.

Accelerated Osteogenic Orthodontics (AOO) concept appeared by 2001; combining selective partial decortications and bone graft. This method could accelerate tooth movement with the ability to reshape and increase the buccolingual thickness of the alveolar bone ${ }^{(3)}$.Periodontally accelerated osteogenic orthodontics (PAOO) concept; is the combination of both the autogenous graft of bone with the assistance of corticotomy for acceleration of orthodontic tooth movement. Both methods AOO and PAOO shown to be effective approaches in adults to decrease treatment time, root resorption and allow bone augmentation ${ }^{(4)}$.

Conventional corticotomy techniques using burs and chisels were exclusively used. It was reported that rotary bur can make fast, deep cuts, but despite maximum caution measures; injuries caused by compression or direct trauma could not be excluded. ${ }^{(5)}$.

Piezo-surgery instrument was first developed in 1988, this method was introduced by using an ultrasonic machine with a modulated frequency that gives a very precise cutting edges in the bone. This procedure is very safe as the nerves, vessels and soft tissues are not affected harmfully by the vibration the ultrasonic instrument, as its already adjusted before procedure to target only hard bony tissue. A very low bleeding tendency is also maintained by the selective and thermal harmless feature of the Piezo method of acceleration.

Piezocorticotomy involves gingival micro incisions or vertical incisional cuts in the cortical bone which may be with flap and may not. The piezotome can be used also in extracted teeth sockets to remove bundle bone easily from the walls of the socket and this is done to lower the resistance of the tooth during movement in orthodontic treatment. Piezocision is 1.5 times faster than conventional orthodontics. A study conducted to compare between the transversal changes during canine retraction and the extend of distalization of the same tooth among patients with upper premolar extraction during orthodontic treatment. Those patients are divided into two groups, the first was with piezocision and the other without. The Piezo group gives results of acceleration during retraction in compare to the piezo free (control) side. Also, results were sufficient to show that the investing group was free from any maxillary transversal changes and in this study there was decrease in loss of anchorage among posterior teeth ${ }^{(7)}$.

In a study the piezoelectric instrument vibration was investigated for its potential use in periodontal therapy and it produced excellent wound healing results ${ }^{(8)}$.

In 2016; a study published evaluating the corticotomy efficiency in orthodontics and precision regarding canine retraction. Extraction of the first bicuspid teeth in the upper arch was required to give sufficient space to evaluate canine retraction. They concluded that both modules are efficient in treatment acceleration regarding canine retraction ${ }^{(9)}$.

In 2016; piezocicsion technique was able to reduce treatment time overall by about $43 \%$ when supported by piezocision comparing this to the control group. But on the other hand in about $50 \%$ of the piezocision applied group scares were observed ${ }^{(10)}$. 
In 2017; a study reported a significant reduction of treatment duration in the piezocision group ${ }^{(11)}$.

Stem cells are unspecialized cells and have the potential to become one or more specialized cell types. Stem cells have the ability to divide to give rise to both daughter cells and more specialized function cells ${ }^{(12)}$.

Orthodontic tooth movement (OTM) achieved by alveolar bone response to applied pressure and PDL remodeling under various mechanical loading forces. Constriction of the periodontal ligaments cases the install inflammation in the sites of pressure which lead to focal necrosis and osteoclasts calling from adjacent to marrow spaces. These last mostly come from hematopoietic stem cells. Regarding, stem cells may be used in orthodontic tooth movement to aid in acceleration by providing progenitor cells ${ }^{(13-15)}$. Stem cell therapy has the ability to accelerate alveolar bone regeneration ${ }^{(16)}$.

In (2012); corticotomy and tissue engineering for orthodontics was discussed from historical point of view and so the new way of thinking to open a new gate for treatment. The article was explain how to utilize the benefits of both corticotomy facilitated orthodontics combined to tissue engineering which includes the stem cells therapy as a new era in medicine, dentistry and orthodontics ${ }^{(17)}$.

In (2012); corticotomy and stem cell therapy have been discussed as a beneficial concept for orthodontists and periodontists. The topic had an overview for Rationale, Hypotheses and Protocol of corticotomy and stem cell therapy. This attempt aimed to enlarge the dental arch basis more speedily, without pain, and with less tissue morbidity than other methods. The incorporation of stem cell therapy is an important element for a wider age of tissue engineering in the twenty first century ${ }^{(18)}$.

The aim of this study was to determine the efficacy of stem cells and corticotomy on the rate of canine retraction.

\section{SUBJECTS AND METHODS}

The study was designed as a randomized controlled clinical study. Twenty two patients were randomly divided into two groups with eleven patients each.These patients were selected from those attending the outpatient clinic, Department of Orthodontics, Faculty of Dental Medicine for Girls, Al Azhar University. All procedures were explained for all patients, informed consent was assigned.

Inclusion criteria for this study werepatients in need to extract four first premolars. Full retraction of the maxillary and mandibular canines with moderate anchorage needed as a part of the orthodontic treatment plan. All permanent teeth other than the third molars were present and fully erupted in both arches and good oral hygiene.

The first group; the control group went through conventional dental orthodontic treatment and canine retraction without any surgical procedure.

The second group; the study group employed the split mouth technique; where both right and left canines of the same patient distributed randomly; In one side piezocorticotomy was done distal to the canine using flap technique, while in the other side piezocorticotomy was done distal to the canine using flap technique then a scaffold holding stem cells was added.

All subjects included in this study were subjected to the following records: extra-oral photograph, Intra-oral photograph, Impression of upper and lower arches to prepare orthodontic study cast, panoramic radiograph, lateral cephalometric radiograph and probing depth was measured just before surgery.

\section{Operative procedures}

\section{In the study group}

Firstextraction of the first premolars, then a conservative incision gingivally was done in the position of the canine till second premolar. A single vertical piezoelectric cut was made distal to the canine on the 
buccal side using tunneling technique, using NSK ultrasonic bone surgery system Variosurg 3 on program 4 at power $150 \%$ with NSK SG4 Variosurg tip. Fig (1-a)

In piezocorticotomy side; After extraction and piezocorticotomy; flap incision was gently closed by sutures.

In the study side; stem cells prepared on the scaffold were adapted distal to the canine and in to the extraction socket and then scoring of the flap incision was done to allow closure of the socket.

\section{For Stem Cells Extraction}

A bone trucker with gauge 25 was inserted on the outer buccal cortex lateral to external oblique ridge of mandibular ramus to reach the mandibular bone marrow. Then the trucker was connected to a syringe with gauge 25 containing $5 \mathrm{ml}$ ( 0.5 heparin and 4.5 saline) to prevent coagulation. This syringe was used to pump out the mandibular bone marrow, during each surgery $\sim 8-10 \mathrm{ml}$ bone marrow was pumped (according to each patient). Fig (1-b)

Ficoll separation technique was used to isolate the stem cells. The isolated bone marrow $10 \mathrm{ml}$ with heparin and saline $5 \mathrm{ml}$; these $15 \mathrm{ml}$ were then divided in two centrifugal tubes and each containing $3 \mathrm{ml}$ ficoll then centrifuge was done at speed 3500 for 20 minutes. Each tube after centrifuge had four separate layers; yellow, turbid cloudy layer (stem cells), clear layer and deep red layer (red blood cells). Fig (1-c). The stem cells were isolated and added to the scaffold (Equispon absorbable gelatin sponge). Fig (1-d)
The scaffold containing stem cells was adapted distal to the canine and into the extraction socket of stem cellsside.

Post-operative instructions were similar to those following any minor oral surgery. Only panadoland alphintern were prescribed after surgery.

The distal retraction of the right and left canines; was performed using a closed NiTi coil spring. The closed NiTi coil spring delivered 150 gm of force in all groups.

To measure canine retraction; impressions were taken every month till complete canine retraction.

The models were then scanned from an occlusal perspective using digital scanner (Identica hyprid). For each case all casts were superimposed by setting the pre- retraction scan as reference and each of post retraction scans as a test by using software (Mimics medical 19.0).

Vertical plane line: for the upper cast models; incisive papilla mid line with median palatine raphe were used to draw mid line vertical plan. For the lower cast models; mid line of the teeth was used to draw mid line vertical plan.

Horizontal plane line: for upper and lower cast models; was drawn tangent to the most posterior convex point on the cast distal to the most fully erupted tooth (distal to upper and lower second molars).

Both planes vertical and horizontal were perpendicular to each other. Two perpendicular

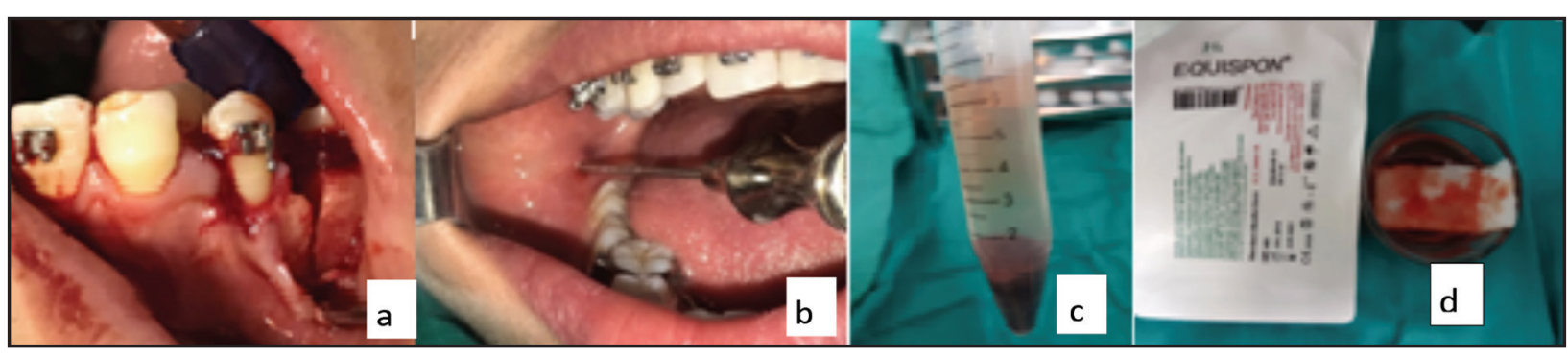

Figure(1) a: buccal piezocorticotomy cut.-b: point of insertion of the bone trucker.-c: isolated bone marrow after centrifuge.-d: stem cells added to adsorbable scaffold. 
lines were drawn one from the right and one from the left canine cusp tip to the vertical line forming two points used for measurement of canine anteroposterior movement.

The distances between each of these two points and the horizontal plane line were measured.

\section{RESULTS}

Clinically; 22 patients had successful healing and complete canine retraction.

Statistical analysis was done for all collected data using ANOVA test, Kruskal-Wallis test, Friedman's test, Dunn's test. The significance level was set at $\mathrm{P} \leq 0.05$. Statistical analysis was performed with IBM SPSS Statistics for Windows, Version 23.0. Armonk, NY: IBM Corp.

\section{Upper arch statistical analysis;}

- The difference wasn't significant statistically between total rates of canine retraction in all groups regarding the maxillary arch only. Fig (2)
- Pair-wise comparisons between the groups revealed that stem cells group showed the statistically significantly highest median rate of upper canine retraction during the first month of retraction. Table (1)

\section{Lower arch statistical analysis;}

- In lower arch the difference was not significant statistically between the stem cells and Piezo groups; both showed statistically significantly higher mean total rates of lower canine retraction than control group. Fig (2)

- Pair-wise comparisons between the groups revealed that stem cells group showed the statistically significantly highest median rate of lower canine retraction during the first and second months. Table (2)

- In stem cells, Piezo and control groups; the mean total canine retraction rates of the upper arch showed statistically significantly higher value than lower arch. Fig (2)

Table 1: Descriptive statistics and results of Kruskal-Wallis test for comparison between rates of upper canine retraction in the three groups.

\begin{tabular}{|c|c|c|c|c|c|c|c|c|}
\hline \multirow{2}{*}{ Time } & \multicolumn{2}{|c|}{ Stem cells } & \multicolumn{2}{|c|}{ Piezo } & \multicolumn{2}{|c|}{ Control } & \multirow{2}{*}{$P$-value } & \multirow{2}{*}{$\begin{array}{c}\text { Effect size } \\
\text { (Eta Squared) }\end{array}$} \\
\hline & Median & Range & Median & Range & Median & Range & & \\
\hline $\mathrm{T} 1$ & $2.23^{\mathrm{A}}$ & $1.32-3.45$ & $1.44^{\mathrm{B}}$ & $0.68-2.28$ & $0.6^{\mathrm{C}}$ & $0.3-1.63$ & $<0.001 *$ & 0.580 \\
\hline $\mathrm{T} 2$ & $2.71^{\mathrm{A}}$ & $1.66-3.43$ & $2.22^{\mathrm{A}}$ & $0.39-2.69$ & $0.5^{\text {в }}$ & $0.04-0.9$ & $<0.001 *$ & 0.605 \\
\hline $\mathrm{T} 3$ & $1.53^{\mathrm{A}}$ & $0.2-1.89$ & $1.74^{\mathrm{A}}$ & $1.32-3.8$ & $0.9^{\text {в }}$ & $0.3-1.6$ & $0.009^{*}$ & 0.305 \\
\hline $\mathrm{T} 4$ & 1 & $0.11-1.11$ & 0.74 & $0.06-1.94$ & 0.6 & $0.31-1.3$ & 0.969 & 0.108 \\
\hline $\mathrm{T} 5$ & - & - & 0.06 & $0.02-0.39$ & 0.8 & $0.13-1.53$ & $0.021^{*}$ & 0.436 \\
\hline T6 & - & - & - & - & 1.1 & $0.2-1.7$ & & $\mathrm{NC}^{\mathrm{i}}$ \\
\hline $\mathrm{T} 7$ & - & - & - & - & 0.9 & $0.34-1.5$ & & $\mathrm{NC}^{\mathrm{i}}$ \\
\hline
\end{tabular}

*: Significant at $P \leq 0.05$, Different superscripts in the same row indicate statistically significant difference between groups, $N C^{i}$ : Not Computed because there is only data for control group. 
Table 2: Descriptive statistics and results of Kruskal-Wallis test for comparison between rates of lower canine retraction in the three groups.

\begin{tabular}{|c|c|c|c|c|c|c|c|c|}
\hline \multirow{2}{*}{ Time } & \multicolumn{2}{|c|}{ Stem cells } & \multicolumn{2}{|c|}{ Piezo } & \multicolumn{2}{|c|}{ Control } & \multirow{2}{*}{$P$-value } & \multirow{2}{*}{$\begin{array}{c}\text { Effect size } \\
\text { (Eta Squared) }\end{array}$} \\
\hline & Median & Range & Median & Range & Median & Range & & \\
\hline $\mathrm{T} 1$ & $2.07^{\mathrm{A}}$ & $1.16-2.63$ & $1.21^{\mathrm{B}}$ & $0.44-2.17$ & $0.3^{\mathrm{C}}$ & $0.2-0.4$ & $<0.001 *$ & 0.782 \\
\hline $\mathrm{T} 2$ & $2.24^{\mathrm{A}}$ & $1.27-2.76$ & $1.39^{\mathrm{B}}$ & $0.8-2.64$ & $0.5^{\mathrm{C}}$ & $0.2-0.7$ & $<0.001 *$ & 0.710 \\
\hline $\mathrm{T} 3$ & $1.11^{\mathrm{A}}$ & $0.23-1.99$ & $1.3^{\mathrm{A}}$ & $0.9-1.74$ & $0.6^{\mathrm{B}}$ & $0.2-0.89$ & $0.002 *$ & 0.446 \\
\hline $\mathrm{T} 4$ & 0.38 & 0.09-0.89 & 0.6 & $0.25-1.62$ & 0.5 & $0.3-0.8$ & 0.474 & 0.028 \\
\hline T5 & - & - & 0.74 & $0.47-1$ & 0.6 & $0.2-1.2$ & 0.636 & 0.222 \\
\hline T6 & - & - & - & - & 0.84 & $0.3-1.05$ & & $\mathrm{NC}^{\mathrm{i}}$ \\
\hline $\mathrm{T} 7$ & - & - & - & - & 1.02 & $0.19-1.5$ & & $\mathrm{NC}^{\mathrm{i}}$ \\
\hline
\end{tabular}

*: Significant at $P \leq 0.05$, Different superscripts in the same row indicate statistically significant difference between groups

$N C^{i}$ : Not computed because there is only data for control group.

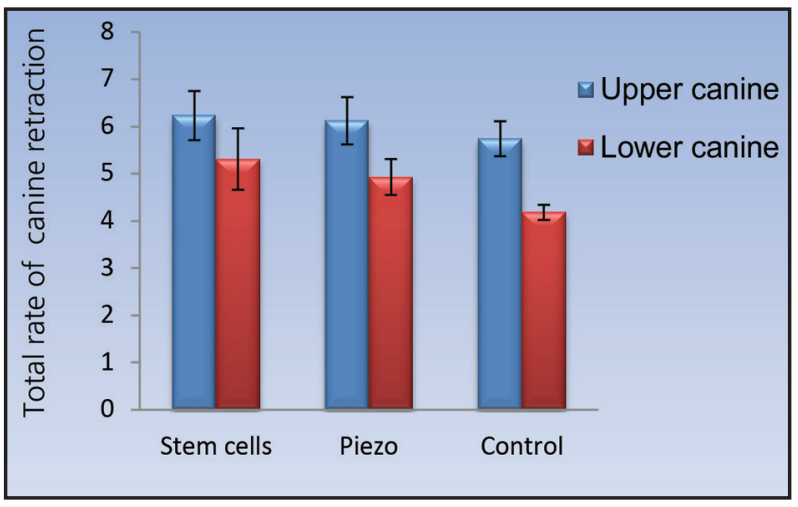

Figure (2) Total rates of upper and lower canine retraction (mean and standard deviation).

\section{DISCUSSION}

Alveolar corticotomies and many other approaches that aim to reduce the time required for orthodontic therapy; these approaches have brought better results but they are not the ultimate solution, newer technologies are always welcomed. Technologies such as stem cell therapy hold a great potential and can bring a revolutionary change ${ }^{(15-19)}$. This study was to discover the effect of adding stem cells therapy to piezocorticotomy approach.
Mandibular bone marrow mesenchymal stem cells were used as they are skeletal tissue cells progenitor as they produce bone, cartilage, supporting stroma, and also adipocytes ${ }^{(20)}$. Mandibular bone marrow mesenchymal stem cells are higher in population and in rate of proliferation when put in comparison to those stem cells of the long bone marrow mesenchymal tissue ${ }^{(21)}$. MSCs percentage in population of mononuclear cell achieved and collected from both iliac crest and mandible are similar ${ }^{(22)}$.

As regards the rate of canine retraction in maxilla there was no statistically significant difference between total rates of upper canine retraction in the three groups. Difference appeared in the mean value; in stem cells group ( $M V=6.23$ ), piezo group ( $\mathrm{MV}=6.12)$, and control group ( $\mathrm{MV}=5.4)$. In stem cells group complete canine retraction was achieved maximum in four months, in piezo group it took up to five months, while in control group it took up to seven months. On the other hand, piezocorticotomy in previous studies showed to be clinically significant faster but statistically no significant compared to conventional treatment ${ }^{(9-23)}$, while in other studies showed clinical and statistical significance ${ }^{(10-11)}$. 
Although in the first month stem cells group showed statistically significantly highest median rate of upper canine retraction, followed by the piezo group. While the control group showed the statistically significantly lowest median rate of upper canine retraction. In the second and third month; there was no statistically significant difference between stem cells and Piezo groups; both showed statistically significantly higher median rates of upper canine retraction than control group. Acceleration in stem and piezo groups was declined by time which was reported in similar studies ${ }^{(24)}$.

As regards the rate of canine retraction in the lower arch; there was no difference in significance between stem cells (MV=5.31) and Piezo (MV=4.93) groups; both showed statistically significantly higher mean total rates of lower canine retraction than control (MV=4.18) group. Stem cells group took up to four months to reach complete canine retraction, piezo group took up to five months, while control group took up to seven months.

In first and second month; stem cells group showed the statistically significantly highest median rate of lower canine retraction. Piezo group showed statistically significantly lower median rate. Control group showed the statistically significantly lowest median rate of lower canine retraction.

In third month; also no difference was found by statistical analysis between stem cells and Piezo groups; both showed statistically significantly higher median rates of lower canine retraction than control group.

In similar studies it was reported that piezocorticotomy could accelerate orthodontic tooth movement. ${ }^{(25-29)}$

In stem cells, Piezo and control groups; the total canine retraction rates of the upper arch showed statistically significantly higher value than the lower arch. This may be due different types of bone and difference in their vascularity.

\section{CONCLUSIONS}

- Higher canine retraction rate in upper arch stem cells group than piezo group only in the first month.

- Higher canine retraction rate in lower arch stem cells group than piezo group only for the first two months.

\section{CONFLICT OF INTEREST}

None declared.

\section{FUNDING}

No funding was received for this study.

\section{REFERENCES}

1. Miles P. Accelerated orthodontic treatment - what's the evidence? Aust. D.J. 2017; 62: 63-70.

2. Isha A, Madhurima N, Manu W, Vishesh D. Surgical Methods to Enhance Orthodontic Tooth Movement: A Review. Int Research J Cl Medicine. 2016; 1: 4.

3. Wilcko W, Wilcko T, Bouquot E. Rapid orthodontics with alveolar reshaping: two case reports of crowding. Int $\mathrm{J}$ Perio. Rest. Dent. 2001; 21: 9-19.

4. Nowzari H, Yorita F K, Chang H. Periodontally accelerated osteogenic orthodontics combined with autogenous bone grafting. CompendContinEduc Dent. 2008; 29: 20-6.

5. Khambay B, Walmsley A. Investigations in to the use of an ultrasonic chisel to cut bone. Part 1: forces applied by clinicians. J Dent. 2000; 28: 31-7.

6. Nazarov A. Improved retention following corticotomy using ABO (objective grading system). Master thesis. St. Louis, MS: 2003.

7. Vercellotti T. Technological characteristics and clinical indications of piezoelectric bone surgery. Minerva Stomatol. 2004; 53:207-14.

8. Tomaso V, Marc L, David M, Myron N, Keisuke W, Robert $\mathrm{S}$, et al. Osseous response following respective surgery with piezosurgery. Int J Periodontics Restorative Dent. 2005; 25: 543-9.

9. Abbas N H, Sabet N E, Hassan I T. Evaluation of corticotomy-facilitated orthodontics and piezocision in rapid canine retraction. Cairo, Egypt. Am J OrthodDentofacialOrthop. 2016; 149: 473-80. 
10. Charavet C, Lecloux G, Bruwier A, Rompen E, Maes N, Limme M, Lambert F. Localized piezoelectric alveolar decortications for orthodontic treatment in adults. A randomized clinical trial. J Dent Res. 2016; 95: 1003-9.

11. Jianru Y, Jiani X, Yu L, Xiaobing L, Zhihe Z. Efficacy of piezocision on accelerating orthodontic tooth movement: A systematic review. Angle Orthod. 2017; 87: 491- 8 .

12. Kaukua N, Fried K, Mao J. Tissue Engineering in Orthodontics Therapy. Integrated Clinical Orthodontics, First Edition. Edited by Vinod Krishnan, Ze'ev Davidovitch. $2012 ; 2: 366-77$.

13. Safari S, Mahdian A, Motamedian S R. Applications of stem cells in orthodontics and dentofacial orthopedics: Current trends and future perspectives. World J Stem Cells. 2018; 10: 66-77.

14. Begum M, Antony T. Role of stem cells in orthodontics A Review. Indian J. of Medical Research and Pharma Sc. 2016; 3:349-534.

15. Mohanty P, Prassed N, Sahoo N, Mohanty G, Sushila S. Reforming craniofacial orthodontics via stem cells. Journal of Intern Society of Preventive and Community Dent. 2015; 5: 13-8.

16. Kabir R, Gupta M, Aggarwal A, Sharma D, Sarin A, Kola M. Imperative role of dental pulp stem cells in regeneration therapies. A system. Rev. Nigger J Surg. 2014; 20; 1-8.

17. Murphy N, Bissada N, Davidovitch Z. Corticotomy and Stem Cell therapy for orthodontists and periodontists: Rationale, Hypotheses and Protocol. I ClinOrthod $1^{\text {st }}$ ed. 2012; 21: 392-421.

18. Murphy N, Bissada N, Davidovitch Z, Kuckska S, Bergman RT, Dashe J, et al.Corticotomy and tissue engineering for orthodontics: A critical history and commentary. SeminOrtod. 2012; 4: 295-307.
19. Ekizera A, Yalvacb M E, Uysalc T, Sonmezd M F, Sahine F. Bone marrow mesenchymal stem cells enhance bone formation inorthodontically expanded maxillae in rats Angle Orthod. 2015; 85: 394-9.

20. Bianco P, Riminucci M, Gronthos S, Robey PG. Bone marrow stromal stem cells: nature, biology and potential applications. Stem Cells. 2001; 19: 3: 92-180.

21. Yamaza T, Ren G, Akiyama K, Chen C, Shi Y, and Shi S. Mouse Mandible Contains Distinctive Mesenchymal Stem Cells. J. Dent. Res. 2011; 3: 317-24.

22. Lee BK, Choi SJ, Mack D, Oh SH. Isolation of mesenchymal stem cells from the mandibular marrow aspirates. Journal of Oral Surg Oral Med Oral Path Oral Rad. 2011; 6: 86-93.

23. Jofre, J., Montenegro J., Arroyo R. Rapid orthodontics with flapless piezoelectric corticotomies: First clinical experiences. Int. J. Odontostomat. 2013; 7: 79-85.

24. Jahanbakhshi M R, Motamedi A M K, Feizbakhsh M, Mogharehabed A. The effect of buccal corticotomy on accelerating orthodontic tooth movement of maxillary canine. Dent Res J (Isfahan).2016; 13: 303-8.

25. Anholm JM, Crites DA, Hoff R, Rathbun WE. Corticotomyfacilitated orthodontics. Callf Dent Assoc J 1986; 14: 7-11.

26. Heider AM. Clinical and radiographic evaluation of advanced osteogenic orthodontics (Ph.D Thesis). Faculty of oral and dental Medicine Cairo University, 2007.

27. Lino S, Sakoda S, Ito G, Nishimori T, Ikeda T and Miyawaki $\mathrm{S}$. Acceleration of orthodontic tooth movement by alveolar corticotomy in dogs. Am J OrthodDentofacialOrthop 2007; 131: 441-8.

28. Della Rocca G. The science of ultrasound therapy for fracture healing. Indian J Orthop. 2009; 43: 121-6.

29. Abbas I T Moutamed G M. Acceleration of orthodontic tooth movement by alveolar corticotomy using piezosurgery. J. of Am. Science. 2012; 8:2- 3. 